\title{
Role of the Orexin System on the Hypothalamus-Pituitary-Thyroid Axis
}

\author{
Antonietta Messina ${ }^{1 \dagger}$, Carolina De Fusco ${ }^{1 \dagger}$, Vincenzo Monda ${ }^{1}$, Maria Esposito ${ }^{2}$, \\ Fiorenzo Moscatelli ${ }^{3}$, Anna Valenzano ${ }^{3}$, Marco Carotenuto ${ }^{2}$, Emanuela Viggiano ${ }^{1}$, \\ Sergio Chieffi ${ }^{1}$, Vincenzo De Luca ${ }^{4}$, Giuseppe Cibelli ${ }^{3}$, Marcellino Monda ${ }^{1}$ and \\ Giovanni Messina ${ }^{1,3 *}$
}

\begin{abstract}
'Department of Experimental Medicine, Section of Human Physiology and Unit of Dietetic and Sport Medicine, Second University of Naples, Naples, Italy, ${ }^{2}$ Neapolitan Brain Group (NBG), Clinic of Child and Adolescent Neuropsychiatry, Department of Mental, Physical Health and Preventive Medicine, Second University of Naples, Naples, Italy, ${ }^{3}$ Department of Clinical and Experimental Medicine, University of Foggia, Foggia, Italy, ${ }^{4}$ Department of Psychiatry, University of Toronto, Toronto, ON, Canada
\end{abstract}

Hypocretin/orexin (ORX) are two hypothalamic neuropeptides discovered in 1998. Since their discovery, they have been one of the most studied neuropeptide systems because of their projecting fields innervating various brain areas. The orexinergic system is tied to sleep-wakefulness cycle, and narcolepsy is a consequence of their system hypofunction. Orexinergic system is also involved in many other autonomic functions such as feeding, thermoregulation, cardiovascular and neuroendocrine regulation. The main aim of this mini review article is to investigate the relationship between ORX and thyroid system regulation. Although knowledge about the ORX system is evolving, its putative effects on hypothalamic-pituitary-thyroid (HPT) axis still appear unclear. We analyzed some studies about ORX control of HPT axis to know better the relationship between them. The studies that were analyzed suggest Hypocretin/ORX to modulate the thyroid regulation, but the nature (excitatory or inhibitory) of this possible interaction remains actually unclear and needs to be confirmed.

Keywords: orexin, posterior lateral hypothalamic area, neuroendocrine control, HPT axis, autonomic functions

\section{INTRODUCTION}

Some recent studies in the literature have reported the existence of a novel family of biologically active neuropeptides, selectively isolated from the mammalian hypothalamus, named orexins (ORX; Sakurai et al., 1998; de Lecea et al., 1998). The ORX, including ORX-A and ORX-B (also termed as hypocretin-1 and hypocretin-2), derive from the proteolytic cleavage of a common 130-amino-acid precursor named preproorexin (Gotter et al., 2012), identified in an intracellular calcium influx assay as endogenous peptide ligands for multiple orphan $G$ protein-coupled cell surface receptors (Sakurai et al., 1998). ORX-A was initially described as an appetite-stimulating factor following local injection of ORX-A into hypothalamic areas such as the dorsomedial hypothalamus (DMH; Dube et al., 1999; De Luca et al., 2008; Viggiano et al., 2009), and in the lateral hypothalamic area (LHA), where feeding behavior and energy balance are regulated (Russell et al., 2002; Sellayah and Sikder, 2013). de Lecea et al. (1998) and Sakurai et al. (1998) observed that ORX share structural similarity with the secretin-related peptides, so they named them hypocretin-1 and hypocretin-2 (Hcrt-1 and Hcrt-2) to identify them as a hypothalamic member of the incretin family (Gotter et al., 2012). At the same time, Sakurai et al. (1998) reported 
that central administration of these peptides stimulated feeding, so they renamed them ORX-A and ORX-B (from the Greek word for appetite, "orexis"). Mammalian ORX are 28 and 33-amino acid peptides, respectively, encoded by a single mRNA transcript, with a $46 \%$ amino acid sequence identity. They are encoded by a gene located in the chromosome 17q21-q24. Their actions are mediated through binding and activating of two closely related G-protein coupled receptors, respectively called orexin receptor 1 (OX1R), and orexin receptor-2 (OX2R), belonging to the rhodopsin-like family A GPCRs. These receptors display different affinity for ORX. The OXR1 has less affinity for ORX-A than for ORX-B. Conversely, OXR2 shows similar affinities for both peptides (Di Bernardo et al., 2014; Esposito et al., 2014b; Monda et al., 2014).

Studies showed that electrical stimulation of the LHA induced morphological changes in the thyroid gland (López et al., 2010). In addition, Kaufman et al. (1986) demonstrated that rats with lesions in the LHA showed lower triiodothyronine (T3) and thyroxine (T4) levels; while, Suzuki et al. (1982) demonstrated that the administration of thyroid-releasing hormone (TRH) in the LHA had a marked anorectic effect. Overall, these data suggest that ORX could modulate the hypothalamic-pituitary-thyroid (HPT) axis. This idea was supported by studies demonstrating that peripheral ORX-A administration in rats inhibits the TRH release from the hypothalamus (Mitsuma et al., 1999), resulting in a fall in the levels of thyroid-stimulating hormone (TSH; Mitsuma et al., 1999; Novak and Levine, 2009). This effect appears to be entirely mediated by the decrease in TRH levels, because both ORX-A and ORX-B failed to inhibit TSH secretion in primary cultures from rat pituitary (Samson and Taylor, 2001). It has been suggested that this lack of effect could be based on the slow metabolism of thyroid hormones (THs; Novak and Levine, 2009), which normally show a delay in their secretory responses to modulatory factors (Kim et al., 2000).

\section{OREXIGENIC SYSTEM}

ORX are selectively expressed by few neurons located within the lateral, dorsomedial and perifornical areas of the hypothalamus (Messina et al., 2014a; Viggiano et al., 2014). Although orexinergic peptides are produced by a discrete neuronal population with a specific anatomical origin, their projection fields have been identified in various brain areas, including thalamus, hypothalamus, cerebral cortex and brainstem (Date et al., 1999; Nambu et al., 1999; Messina et al., 2014b). Based on this unique pattern of ORX-containing fiber distribution and the functional activation of neural circuits, the pleiotropic functions of ORXs and their involvement in the coordination of multiple versatile physiological processes, such as sleep-wakefulness, arousal, energy balance, narcolepsy, glucose metabolism, gastric ulcers and thermogenesis were proposed (Szlachcic et al., 2013; Tsujino and Sakurai, 2013; Giardino and de Lecea, 2014).

Other studies suggest that the ORX system could modulate the HPT axis. In fact, the peripheral ORX-A administration in rats inhibits TRH release from the hypothalamus (Mitsuma et al., 1999), resulting in a fall of TSH levels (Russell et al., 2000). This effect appears to be entirely mediated by the decrease in TRH levels, because both ORX-A and ORX-B failed to inhibit TSH secretion in primary cultures from rat pituitary (Samson and Taylor, 2001). Curiously, plasma TH levels showed no changes after peripheral ORX-A administration (Mitsuma et al., 1999). It has been suggested that this lack of effect could be based by the slow metabolism of TH (Russell et al., 2000), which normally shows a delay in its secretory responses to modulatory factors (Kim et al., 2000).

Moreover, ORXs can modulate the activity of both the locus coeruleus (LC) and the basal forebrain neurons involved in the complex mechanism of arousal (Berridge et al., 2010; Tortorella et al., 2013), thus playing a relevant role in arousal during waking and suppressing rapid eye movement (REM) sleep (Hagan et al., 1999; Bourgin et al., 2000; España et al., 2001). As reported by Zitnik (2016) ORX-containing neurons from the hypothalamus innervate LC neurons that project to prefrontal cortex, implicating the involvement of LC in ORX-mediated EEG activation and wakefulness, with specific thalamic-cortical oscillatory rhythms (Del CidPellitero and Garzón, 2011). On the other hand, ORX-mediated activation of the LC appears to be critical not only to maintain wakefulness during the active period, but also in the transition from sleep to waking. Such a transition is attributed to its engagement in neural circuit, contributing to the regulation of circadian rhythms that may exist through ORX-containing neurons in the $\mathrm{DMH}$ projecting to the $\mathrm{LC}$, since it receives projections from the suprachiasmatic nucleus (SCN; Aston-Jones et al., 2001; Gompf and Aston-Jones, 2008).

Indeed, in vitro electrophysiological experiments showed that ORXs activate the tuberomammillary nuclei ablations (TMN; Bayer et al., 2001; Eriksson et al., 2001) and LC neurons (Hagan et al., 1999). Furthermore, in vivo studies demonstrated the involvement of the LC and OX1R in the LC neurons (Mochizuki et al., 2011) and OX2R signaling in the TMN, in ORX-induced arousal. Although conflicting, recent studies have shown that the ORX-mediated sleep-towake transition in mice is not dependent on the histaminergic system and mice deficient in both OX1R and hystamine 1 receptors display normal sleep/wakefulness patterns (Tsujino and Sakurai, 2009). Moreover, T4, entering the brain via the choroid plexus, is preferentially delivered to subependymal brain structures. High concentrations of LC norepinephrine promote active conversion of $\mathrm{T} 4$ to $\mathrm{T} 3$, leading to the preeminence of the LC as a site of T3 concentration (Dratman and Gordon, 1996).

Not secondarily, ORXs seem to play a positive role in the learning and memory functions, suggesting a sort of direct association with the regulation of the arousal system.

In fact, ORXs and their receptors are widely distributed throughout the brain and thereby regulate learning and memory functions (Jaeger et al., 2002; Telegdy and Adamik, 2002; Akbari et al., 2007). Specifically, ORX-A enables the acquisition, consolidation and retrieval of learning and memory 
(Jaeger et al., 2002; Yang et al., 2013). Studies show that ORX-A administered into the brain ventricles in conscious rats facilitates learning and the consolidation of learning, as well as retrieval processes in passive avoidance tests (Jaeger et al., 2002; Telegdy and Adamik, 2002; Ito et al., 2008). On the other hand, the electrical activity of hippocampal pyramidal neuron seems to be under direct control of the ORX system (Riahi et al., 2015), pinpointing the crucial role of hippocampal neurogenesis in learning and memory (Deng et al., 2009; Jessberger et al., 2009; Coras et al., 2010). Studies of behavior and hippocampal synaptic plasticity indicate that $\mathrm{ERK}_{1 / 2}$ activation enhances the induction of long-term potentiation, which contributes to the formation of memories, moreover the improvement in learning and memory mediated by ORX-A involves OX1R-mediated $\mathrm{ERK}_{1 / 2}$ activation and hippocampal neurogenesis (Selcher et al., 2003; Zhao et al., 2014).

It has been suggested that ORX-A is also implicated in the regulation of hormones, including prolactin (PRL; Hagan et al., 1999; Russell et al., 2000) and the luteinizing hormone (LH; Pu et al., 1998; Tamura et al., 1999), and in the control of the hypothalamo-pituitary-adrenal (HPA; Kuru et al., 2000; López et al., 2010), thyroid (Mitsuma et al., 1999; Kok et al., 2005) and somatotropic axes, as well (Hagan et al., 1999; Figure 1).

Conversely, the effect of the ORX system in cognition may be properly explained by its relationship with thyroid function along life span and not only by lowering TSH levels, frequently it related to cognitive impairment or elderly decline (Winkler et al., 2015; Chachamovitz et al., 2016; Moon, 2016). TH plays an essential role in normal brain development and its function linked to the maturation of its receptor in the developing brain. On the other hand, hypothalamus plays a crucial role in the regulation of $\mathrm{TH}$ serum concentrations, since the earliest stages of life (Alkemade, 2015), also causing specific cognitive alteration in progeny (Pasquali et al., 2015).

\section{ROLE OF OREXINS IN ENDOCRINE SYSTEM}

Despite their primary role as hypothalamic neuropeptides, ORXs and OXRs are widely expressed also in regions beyond the brain, in particular in endocrine tissues (Heinonen et al., 2008; Grimaldi et al., 2014). For example, the ORX peptide/receptor

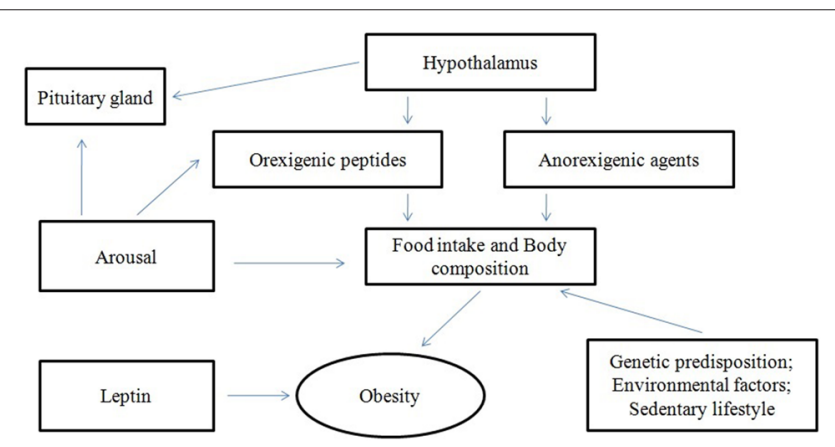

FIGURE 1 | Interactions of orexins (ORX). system was observed in the pituitary (Date et al., 2000; Blanco et al., 2001; Silveyra et al., 2007). The relevance of ORXs in the pituitary is also highlighted by the evidence that ORX-A-like molecule and OX1R are widely present in the adenohypophysis of Xenopus (Suzuki et al., 2007; Chieffi et al., 2014), and this underlines a highly conserved function. In the Xenopus, ORX-A-like substance is synthesized with and/or without TSH from TSH-containing cells and controls the functions of PRLcontaining cells via OX1R in a paracrine fashion. In the Nile tilapia (Oreochromis niloticus, Monda et al., 2008; Suzuki et al., 2009), an ORX-B-like substance might be secreted from LH- or TSH-containing cells and might regulate the pituitary function, as well. Blanco et al. (2001) detected the presence of ORX-A and ORX-B in the human adenohypophysis cell types. The ORX-A was located in $33 \%$ of pituitary cells, including PRL ( $82 \pm 5.3 \%)$, TSH $(18 \pm 2.3 \%)$, growth hormone $(\mathrm{GH} ; 10 \pm 2.3 \%)$, FollicleStimulating Hormone (FSH; $8 \pm 2.6 \%)$ and $\mathrm{LH}(7 \pm 3.2 \%)$ cells, but not in corticotrope cells (Monda et al., 2006, 2007).

In vitro studies showed that ORX-A stimulated PRL and GH secretion (Zieba et al., 2011), and that the intensity of this effect depended on the duration of the day. The PRL secretion stimulated by ORX-A was more intensive in the summer (longday period), than in winter (short-day; Molik et al., 2008).

The ORX-B was observed in virtually all corticotrope cells of the adeno-hypophysis (Viggiano et al., 2010). According to this study, lactotrope cells are the major source of ORX-A and corticotrope cells of ORX-B, respectively, and these observations represent the cellular basis for a possible role of ORXs influencing virtually all the neuroendocrine axis, acting as signal molecules.

Though the adrenal gland seems to be a peripheral target organ for ORXs (Monda et al., 2004), additional studies revealed the presence of ORXs all over the neuroendocrine system, as neurotransmitter peptides in the regulation of $\mathrm{GH}$, adrenocorticotropic hormone, thyroid, mineralocorticoid, and cortisol secretion ( $\mathrm{Pu}$ et al., 1998; Molik et al., 2008; Figure 1).

Moreover, the relationship between thyroid gland metabolism and ORXs is supported by evidence in euthyroid subjects affected by narcolepsy without cataplexy (Sobol and Spector, 2014) and among canine models (Nishino et al., 1997; Riehl et al., 2000) of improvement in subjective sleepiness and mean sleep time in idiopathic hypersomnia due to levothyroxine administration. The proposed mechanisms include HPT axis alteration and/or activation of TSH, TRH, or T3 receptors in the brain's arousalpromoting system (Shinno et al., 2011). On the other hand, low levels of circulating TSH are reported in ORX-deficient narcoleptic men, which could be attributed to low levels of plasma leptin and/or abnormal sleep-wake cycle (Kok et al., 2005). Finally, the prevalence of comorbid immunopathological diseases (also affecting thyroid gland) seems to be higher in subjects with narcolepsy and cataplexy with a significantly more severe prognosis (Martínez-Orozco et al., 2014).

\section{OREXINS AND THE THYROID AXIS}

The TRH is synthesized in the paraventricular nucleus (PVN; Lechan and Jackson, 1982), hosting a lot of neuroendocrine 
parvocellular neurons projecting to the median eminence, thus stimulating TSH secretion through endocrine and paracrine manners, respectively (Moura and Moura, 2004). Therefore, TSH synthesis and secretion are primarily regulated by $\mathrm{TRH}$ release and feedback inhibition by TH. However, PVN is not only the central point of the regulation of hypothalamic-pituitarythyroid (HPT) axis, but it is also among the various brain areas to which orexinergic neurons project (Date et al., 1999). In fact, ORX neurons widely project to the autonomic part of the PVN (Peyron et al., 1998), in a strategic position to modulate the autonomic functions and the endocrine system. However, it is yet unknown whether either the ORX axons actually synapse with TRH neurons, or the ORX peptide/receptor system is involved in the regulation of HPT axis. The aim of this mini review is to investigate the relationship between orexigenic peptides and thyroid. The putative effects of ORX-A on HPT axis appear less clear because of the reported results in animal experiments investigating the effects of orexigenic peptides on the TSH release that appear inconclusive and conflicting. In some studies intracerebroventricular (ICV) injection of ORX-A in rats was shown to acutely decrease TRH release and plasma TSH concentration, with changes in plasma TH levels (Mitsuma et al., 1999). In particular, Mitsuma et al. (1999) observed that TSH suppression was due to in vitro TRH inhibition from the rat hypothalamus, following ORX-A addition, allowing the authors to conjecture that ORX-A was able to inhibit TRH release via the pituitary. Similarly, in another study Russell et al. (2002) observed that ICV administration of ORX-A significantly suppressed plasma TSH, without changes in plasma free T3 or T4 (FT3, FT4). The lack of effect on TH may be due to the low metabolism of TH. In this regard, it has been demonstrated that changes in FT4, occurred $15 \mathrm{~h}$ following iPVN injection (Kim et al., 2000). Besides it, another conflicting result was the lack of changes in plasma TSH, following twice-daily injections of ORX-A into the PVN for 3 days (Bartness et al., 2010). This result suggested the absence of a sustained effect of ORXA chronically administered into the PVN on plasma TSH. Taken together, ORX-A displays no measurable effect on the HTP (Jones et al., 2001), whereas circulating TSH increased in response to central administration of ORX-B. However, Hagan et al. (1999) measured TSH solely at $40 \mathrm{~min}$ post-ICV administration, a time point to which TSH got normalized in Russell's study (Russell et al., 2002), thus determining a confounding result. In another article, López et al. (2010) showed no significant change in hypothalamic prepro-ORX and OXRs mRNA levels in either severe hypo-, or hyperhyperthyroid rats, in comparison to that in euthyroid ones, despite altered leptin levels. Since prepro-ORX-gene expression is regulated by leptin, this may suggest that PVN may not be an important anatomical site for chronic effect of ORX-A in the HPT axis. In a recent study on hyperthyroidism, Tohma et al. (2015) described the effects of hyperthyroidism on ORX-A, to investigate the putative relationship between ORX-A and the increased food intake, which characterizes hyperthyroidism. Although it seems that no link between ORX-A and increased appetite exists in hyperthyroidism, the ORX-A levels were decreased by hyperthyroidism, showing a negative correlation with FT3 and FT4 levels, and a positive correlation with TSH levels. The mechanism of these alterations is actually unknown. Probably, decreased ORX-A levels were the consequence of a compensatory mechanism for the increased basal metabolic rate, characterizing hyperthyroidism (Messina et al., 2015c; Moscatelli et al., 2015). Date et al. (2000) investigated the ORX-A levels in adult male rats affected by hyperthyroidism, observing no differences in ORX-A mRNA levels, caused by hyperthyroidism. Conversely, Kok et al. (2005) found changes in TSH concentration. Moreover, to investigate the impact of ORX-A upon the HPT axis, the circadian timing of its release was studied in a group of narcoleptic patients (Messina et al., 2015b; Triggiani et al., 2015; Valenzano et al., 2016).

In conclusion, this study showed that plasma TSH levels were reduced and were positively correlated to leptin plasma levels that could be the presumable cause of reduced TSH (Messina et al., 2015a). Moreover, among narcoleptic patients, energy imbalance, eating disorders (Chabas et al., 2007), precocious puberty, obesity and changes in bicarbonate levels are more frequent than in healthy subjects, also during childhood (Poli et al., 2013; Rocca et al., 2015; Franco et al., 2016).

Nevertheless, the relationship between leptin, sleep regulation and thyroid gland, as resumed in obese patients, affected by obstructive sleep apnea syndrome (OSAS) has to be considered. In fact, in these subjects, the nocturnal respiratory imbalance is a typical integrative part of the metabolic syndrome (Vgontzas et al., 2005; Basoglu et al., 2011). Moreover, there is an inverse link between sleep duration and body mass index, due to the increased levels of leptin and other systemic inflammatory markers during lifetime, which is independent of obesity in adults (Vgontzas et al., 2016). On the other hand, in non obese men and slightly obese women OSAS is similarly associated with HPA axis activation, albeit stronger, compared with obese individuals with sleep apnea (Kritikou et al., 2016), although with specific gender differences (Gaines et al., 2014). Again, acute sleep loss, in a less stressful environment, influences leptin levels in a way opposite to that of short-term sleep curtailment, associated with activation of the stress system. It is likely that sleep loss, associated with activation of the stress system, but not sleep loss per se, may lead to increased hunger and appetite and hormonal changes, which ultimately may lead to increased consumption of "comfort" food and thereby to obesity (Pejovic et al., 2010), because changes in energy homeostasis directly and reversibly impact the sleep/wake cycle (Collet et al., 2016).

About the role of thyroid ghrelin, leptin, and insulin levels did not differ accordingly to thyroid function conditions (Dubey et al., 2015; Kim et al., 2015), although leptin levels seem to correlate with thyroid autoantibody titers in non obese males (Maciver et al., 2015). More specifically, pediatric obesity is associated with higher TSH and lower FT4 concentrations and with a greater prevalence of abnormally high TSH and leptin concentrations that might in part explain obesity's effects on thyroid status, perhaps through leptin's influences on TSH secretion (Krause et al., 2016). In this framework, it has been well recognized that ORX neurons are regulated by peripheral metabolic cues, including ghrelin, leptin and glucose concentration, suggesting that they might provide a link between 
energy homeostasis and arousal states and the link between the limbic system and the ORX neurons might be important for increasing vigilance during emotional stimuli (Carotenuto et al., 2012, 2013; García-García et al., 2014). When imbalanced, such links could explain mood dysregulation and executive function impairment in obese OSAS and insomniac children and adolescents (Esposito et al., 2013, 2014a; Carotenuto et al., 2016).

\section{CONCLUSION}

Although the knowledge of ORXs functions is evolving, studies of the putative effects of orexigenic peptides on the HPT axis remains conflicting and there are still a number of doubts concerning them. In fact, although the topography of ORXs and thyrotrope neural circuits suggests that TRH neuronal activity is influenced by ORX input, the nature of this input and the exact role of ORX (excitatory or inhibitory) remain unclear. However, it is clear that the ORX peptide/receptor system represents a

\section{REFERENCES}

Akbari, E., Naghdi, N., and Motamedi, F. (2007). The selective orexin 1 receptor antagonist SB-334867-A impairs acquisition and consolidation but not retrieval of spatial memory in Morris water maze. Peptides 28, 650-656. doi: 10.1016/j. peptides.2006.11.002

Alkemade, A. (2015). Thyroid hormone and the developing hypothalamus. Front. Neuroanat. 9:15. doi: 10.3389/fnana.2015.00015

Aston-Jones, G., Chen, S., Zhu, Y., and Oshinsky, M. L. (2001). A neural circuit for circadian regulation of arousal. Nat. Neurosci. 4, 732-738. doi: 10.1038/ 89522

Bartness, T. J., Vaughan, C. H., and Song, C. K. (2010). Sympathetic and sensory innervation of brown adipose tissue. Int. J. Obes. (Lond) 34, S36-S42. doi: 10. 1038/ijo.2010.182

Basoglu, O. K., Sarac, F., Sarac, S., Uluer, H., and Yilmaz, C. (2011). Metabolic syndrome, insulin resistance, fibrinogen, homocysteine, leptin and C-reactive protein in obese patients with obstructive sleep apnea syndrome. Ann. Thorac. Med. 6, 120-125. doi: 10.4103/1817-1737.82440

Bayer, L., Eggermann, E., Serafin, M., Saint-Mleux, B., Machard, D., Jones, B., et al. (2001). Orexins (hypocretins) directly excite tuberomammillary neurons. Eur. J. Neurosci. 14, 1571-1575. doi: 10.1046/j.0953-816x.2001.01777.x

Berridge, C. W., España, R. A., and Vittoz, N. M. (2010). Hypocretin/orexin in arousal and stress. Brain Res. 1314, 91-102. doi: 10.1016/j.brainres.2009.09.019

Blanco, M., López, M., GarcIa-Caballero, T., Gallego, R., Vázquez-Boquete, A., Morel, G., et al. (2001). Cellular localization of orexin receptors in human pituitary. J. Clin. Endocrinol. Metab. 86, 1616-1619. doi: 10.1210/jc. 86.4.1616

Bourgin, P., Huitrón-Résendiz, S., Spier, A. D., Fabre, V., Morte, B., Criado, J. R., et al. (2000). Hypocretin-1 modulates rapid eye movement sleep through activation of locus coeruleus neurons. J. Neurosci. 20, 7760-7765.

Carotenuto, M., Esposito, M., Cortese, S., Laino, D., and Verrotti, A. (2016). Children with developmental dyslexia showed greater sleep disturbances than controls including problems initiating and maintaining sleep. Acta Paediatr. doi: 10.1111/apa.13472 [Epub ahead of print].

Carotenuto, M., Esposito, M., Parisi, L., Gallai, B., Marotta, R., Pascotto, A., et al. (2012). Depressive symptoms and childhood sleep apnea syndrome. Neuropsychiatr. Dis. Treat. 8, 369-373. doi: 10.2147/NDT.s35974

Carotenuto, M., Gallai, B., Parisi, L., Roccella, M., and Esposito, M. (2013). Acupressure therapy for insomnia in adolescents: a polysomnographic study. Neuropsychiatr. Dis. Treat. 9, 157-162. doi: 10.2147/NDT.s41892

Chabas, D., Foulon, C., Gonzalez, J., Nasr, M., Lyon-Caen, O., Willer, J.-C., et al. (2007). Eating disorder and metabolism in narcoleptic patients. Sleep 30, 1267-1273. novel molecular model system to understand the regulation of neuroendocrine system.

\section{AUTHOR CONTRIBUTIONS}

CDF, AM, VM, ME: conceived the study, participated in its design and wrote the manuscript. FM, AV, EV, SC, VDL: contributed to the conception and design. MC, GC, MM, GM: drafted the article and revised it critically for important intellectual content. GM: final approval of the version to be published. All authors read and approved the final manuscript.

\section{FUNDING}

This study was supported by grants of Section of Human Physiology and Unit of Dietetic and Sport Medicine and Department of Experimental Medicine, Second University of Naples.

Chachamovitz, D. S., Vigário Pdos, S., Silva, S. O. E., Teixeira, L. B., Fagundes, M. L., Vaisman, M., et al. (2016). Does low-normal serum TSH level adversely impact cognition in elderly adults and might methimazole therapy improve outcomes? Endocr. J. 63, 495-505. doi: 10.1507/endocrj.ej15-0458

Chieffi, S., Iavarone, A., Iaccarino, L., La Marra, M., Messina, G., De Luca, V., et al. (2014). Age-related differences in distractor interference on line bisection. Exp. Brain Res. 232, 3659-3664. doi: 10.1007/s00221-014-4056-0

Collet, T.-H., van der Klaauw, A. A., Henning, E., Keogh, J. M., Suddaby, D. Dachi, S. V., et al. (2016). The sleep/wake cycle is directly modulated by changes in energy balance. Sleep [Epub ahead of print].

Coras, R., Siebzehnrubl, F. A., Pauli, E., Huttner, H. B., Njunting, M., Kobow, K., et al. (2010). Low proliferation and differentiation capacities of adult hippocampal stem cells correlate with memory dysfunction in humans. Brain 133, 3359-3372. doi: 10.1093/brain/awq215

Date, Y., Mondal, M. S., Matsukura, S., Ueta, Y., Yamashita, H., Kaiya, H., et al. (2000). Distribution of orexin/hypocretin in the rat median eminence and pituitary. Brain Res. Mol. Brain Res. 76, 1-6. doi: 10.1016/s0169328x(99)00317-4

Date, Y., Ueta, Y., Yamashita, H., Yamaguchi, H., Matsukura, S., Kangawa, K., et al. (1999). Orexins, orexigenic hypothalamic peptides, interact with autonomic, neuroendocrine and neuroregulatory systems. Proc. Natl. Acad. Sci. U S A 96, 748-753. doi: 10.1073/pnas.96.2.748

Del Cid-Pellitero, E., and Garzón, M. (2011). Hypocretin1/OrexinA-containing axons innervate locus coeruleus neurons that project to the Rat medial prefrontal cortex. Implication in the sleep-wakefulness cycle and cortical activation. Synapse 65, 843-857. doi: 10.1002/syn.20912

de Lecea, L., Kilduff, T. S., Peyron, C., Gao, X., Foye, P. E., Danielson, P. E., et al. (1998). The hypocretins: hypothalamus-specific peptides with neuroexcitatory activity. Proc. Natl. Acad. Sci. U S A 95, 322-327. doi: 10.1073/pnas. 95.1.322

De Luca, V., Viggiano, E., Messina, G., Viggiano, A., Borlido, C., Viggiano, A., et al. (2008). Peripheral amino Acid levels in schizophrenia and antipsychotic treatment. Psychiatry Investig. 5, 203-208. doi: 10.4306/pi.2008.5.4.203

Deng, W., Saxe, M. D., Gallina, I. S., and Gage, F. H. (2009). Adultborn hippocampal dentate granule cells undergoing maturation modulate learning and memory in the brain. J. Neurosci. 29, 13532-13542. doi: 10 1523/JNEUROSCI.3362-09.2009

Di Bernardo, G., Messina, G., Capasso, S., Del Gaudio, S., Cipollaro, M., Peluso, G., et al. (2014). Sera of overweight people promote in vitro adipocyte differentiation of bone marrow stromal cells. Stem Cell Res. Ther. 5:4. doi: 10. $1186 /$ scrt393

Dratman, M. B., and Gordon, J. T. (1996). Thyroid hormones as neurotransmitters. Thyroid 6, 639-647. doi: 10.1089/thy.1996.6.639 
Dube, M. G., Kalra, S. P., and Kalra, P. S. (1999). Food intake elicited by central administration of orexins/hypocretins: identification of hypothalamic sites of action. Brain Res. 842, 473-477. doi: 10.1016/s0006-8993(99) 01824-7

Dubey, A., Kant, S., Tiwari, S., Agarwal, S., and Mahdi, A. A. (2015). Leptin level correlates with obesity and health related quality of life in obstructive sleep apnea syndrome patients. Indian J. Tuberc. 62, 105-109. doi: 10.1016/j.ijtb. 2015.04.010

Eriksson, K. S., Sergeeva, O., Brown, R. E., and Haas, H. L. (2001). Orexin/hypocretin excites the histaminergic neurons of the tuberomammillary nucleus. J. Neurosci. 21, 9273-9279.

España, R. A., Baldo, B. A., Kelley, A. E., and Berridge, C. W. (2001). Wake-promoting and sleep-suppressing actions of hypocretin (orexin): basal forebrain sites of action. Neuroscience 106, 699-715. doi: 10.1016/s03064522(01)00319-0

Esposito, M., Antinolfi, L., Gallai, B., Parisi, L., Roccella, M., Marotta, R., et al. (2013). Executive dysfunction in children affected by obstructive sleep apnea syndrome: an observational study. Neuropsychiatr. Dis. Treat. 9, 1087-1094. doi: $10.2147 /$ NDT.s47287

Esposito, M., Gallai, B., Roccella, M., Marotta, R., Lavano, F., Lavano, S. M., et al. (2014a). Anxiety and depression levels in prepubertal obese children: a casecontrol study. Neuropsychiatr. Dis. Treat. 10, 1897-1902. doi: 10.2147/ndt. s69795

Esposito, M., Serpe, F. P., Diletti, G., Messina, G., Scortichini, G., La Rocca, C., et al. (2014b). Serum levels of polychlorinated dibenzo-p-dioxins, polychlorinated dibenzofurans and polychlorinated biphenyls in a population living in the Naples area, southern Italy. Chemosphere 94, 62-69. doi: 10.1016/j. chemosphere.2013.09.013

Franco, P., Junqua, A., Guignard-Perret, A., Raoux, A., Perier, M., Raverot, V., et al. (2016). High bicarbonate levels in narcoleptic children. J. Sleep Res. 25, 194-202. doi: 10.1111/jsr.12357

Gaines, J., Vgontzas, A. N., Fernandez-Mendoza, J., Kritikou, I., Basta, M., and Bixler, E. O. (2014). Gender differences in the association of sleep apnea and inflammation. Brain Behav. Immun. 47, 211-217. doi: 10.1016/j.bbi.2014. 11.013

García-García, F., Juárez-Aguilar, E., Santiago-García, J., and Cardinali, D. P. (2014). Ghrelin and its interactions with growth hormone, leptin and orexins: implications for the sleep-wake cycle and metabolism. Sleep Med. Rev. 18, 89-97. doi: 10.1016/j.smrv.2013.04.003

Giardino, W. J., and de Lecea, L. (2014). Hypocretin (orexin) neuromodulation of stress and reward pathways. Curr. Opin. Neurobiol. 29, 103-108. doi: 10.1016/j. conb.2014.07.006

Gompf, H. S., and Aston-Jones, G. (2008). Role of orexin input in the diurnal rhythm of locus coeruleus impulse activity. Brain Res. 1224, 43-52. doi: 10. 1016/j.brainres.2008.05.060

Gotter, A. L., Webber, A. L., Coleman, P. J., Renger, J. J., and Winrow, C. J. (2012). International union of basic and clinical pharmacology. LXXXVI. Orexin receptor function, nomenclature and pharmacology. Pharmacol. Rev. 64, 389-420. doi: 10.1124/pr.111.005546

Grimaldi, D., Silvani, A., Benarroch, E. E., and Cortelli, P. (2014). Orexin/hypocretin system and autonomic control: new insights and clinical correlations. Neurology 82, 271-278. doi: 10.1212/WNL.0000000000000045

Hagan, J. J., Leslie, R. A., Patel, S., Evans, M. L., Wattam, T. A., Holmes, S., et al. (1999). Orexin A activates locus coeruleus cell firing and increases arousal in the rat. Proc. Natl. Acad. Sci. U S A 96, 10911-10916. doi: 10.1073/pnas.96.19. 10911

Heinonen, M. V., Purhonen, A. K., Mäkelä, K. A., and Herzig, K. H. (2008). Functions of orexins in peripheral tissues. Acta Physiol. (Oxf.) 192, 471-485. doi: 10.1111/j.1748-1716.2008.01836.x

Ito, N., Yabe, T., Gamo, Y., Nagai, T., Oikawa, T., Yamada, H., et al. (2008). I.c.v. administration of orexin-A induces an antidepressive-like effect through hippocampal cell proliferation. Neuroscience 157, 720-732. doi: 10.1016/j. neuroscience.2008.09.042

Jaeger, L. B., Farr, S. A., Banks, W. A., and Morley, J. E. (2002). Effects of orexin-A on memory processing. Peptides 23, 1683-1688. doi: 10.1016/s01969781(02)00110-9

Jessberger, S., Clark, R. E., Broadbent, N. J., Clemenson, G. D. Jr., Consiglio, A., Lie, D. C., et al. (2009). Dentate gyrus-specific knockdown of adult neurogenesis impairs spatial and object recognition memory in adult rats. Learn. Mem. 16, 147-154. doi: 10.1101/lm.1172609

Jones, D. N. C., Gartlon, J., Parker, F., Taylor, S. G., Routledge, C., Hemmati, P., et al. (2001). Effects of centrally administered orexin-B and orexin-A: a role for orexin-1 receptors in orexin-B-induced hyperactivity. Psychopharmacology (Berl) 153, 210-218. doi: 10.1007/s002130000551

Kaufman, L. N., Corbett, S. W., and Keesey, R. E. (1986). Relationship of thyroid hormones and norepinephrine to the lateral hypothalamic syndrome. Metab. Clin. Exp. 35, 847-851. doi: 10.1016/0026-0495(86)90227-1

Kim, K. J., Kim, B. Y., Mok, J. O., Kim, C. H., Kang, S. K., and Jung, C. H. (2015). Serum concentrations of ghrelin and leptin according to thyroid hormone condition and their correlations with insulin resistance. Endocrinol. Metab. (Seoul) 30, 318-325. doi: 10.3803/EnM.2015.30.3.318

Kim, M. S., Small, C. J., Stanley, S. A., Morgan, D. G. A., Seal, L. J., Kong, W. M., et al. (2000). The central melanocortin system affects the hypothalamopituitary thyroid axis and may mediate the effect of leptin. J. Clin. Invest. 105, 1005-1011. doi: 10.1172/jci8857

Kok, S. W., Roelfsema, F., Overeem, S., Lammers, G. J., Frölich, M., Meinders, A. E., et al. (2005). Altered setting of the pituitary-thyroid ensemble in hypocretin-deficient narcoleptic men. Am. J. Physiol. Endocrinol. Metab. 288, E892-E899. doi: 10.1152/ajpendo.00327.2004

Krause, A. J., Cines, B., Pogrebniak, E., Sherafat-Kazemzadeh, R., Demidowich, A. P., Galescu, O. A., et al. (2016). Associations between adiposity and indicators of thyroid status in children and adolescents. Pediatr. Obes. doi: 10.1111/ijpo.12112 [Epub ahead of print].

Kritikou, I., Basta, M., Vgontzas, A. N., Pejovic, S., Fernandez-Mendoza, J., Liao, D., et al. (2016). Sleep apnoea and the hypothalamic-pituitary-adrenal axis in men and women: effects of continuous positive airway pressure. Eur. Respir. J. 47, 531-540. doi: 10.1183/13993003.00319-2015

Kuru, M., Ueta, Y., Serino, R., Nakazato, M., Yamamoto, Y., Shibuya, I., et al. (2000). Centrally administered orexin/hypocretin activates HPA axis in rats. Neuroreport 11, 1977-1980. doi: 10.1097/00001756-200006260-00034

Lechan, R. M., and Jackson, I. M. (1982). Immunohistochemical localization of thyrotropin-releasing hormone in the rat hypothalamus and pituitary. Endocrinology 111, 55-65. doi: 10.1210/endo-111-1-55

López, M., Tena-Sempere, M., and Diéguez, C. (2010). Cross-talk between orexins (hypocretins) and the neuroendocrine axes (hypothalamic-pituitary axes). Front. Neuroendocrinol. 31, 113-127. doi: 10.1016/j.yfrne.2009.07.001

Maciver, N. J., Thomas, S. M., Green, C. L., and Worley, G. (2015). Increased leptin levels correlate with thyroid autoantibodies in nonobese males. Clin. Endocrinol. (Oxf) 85, 116-121. doi: 10.1111/cen.12963

Martínez-Orozco, F. J., Vicario, J. L., Villalibre-Valderrey, I., De Andrés, C., Fernández-Arquero, M., and Peraita-Adrados, R. (2014). Narcolepsy with cataplexy and comorbid immunopathological diseases. J. Sleep Res. 23, 414-419. doi: 10.1111/jsr.12143

Messina, G., Dalia, C., Tafuri, D., Monda, V., Palmieri, F., Dato, A., et al. (2014a). Orexin-A controls sympathetic activity and eating behavior. Front. Psychol. 5:997. doi: 10.3389/fpsyg.2014.00997

Messina, G., Viggiano, A., Tafuri, D., Palmieri, F., De Blasio, S., Messina, A., et al. (2014b). Role of orexin in obese patients in the intensive care unit. J. Anesth. Clin. Res. 5:395. doi: 10.4172/2155-6148.1000395

Messina, G., Monda, V., Moscatelli, F., Valenzano, A., Monda, G., Esposito, T., et al. (2015a). Role of orexin system in obesity. Biol. Med. 7:4. doi: 10 4172/0974-8369.1000248

Messina, G., Palmieri, F., Monda, V., Messina, A., Dalia, C., Viggiano, A., et al. (2015b). Exercise causes muscle GLUT4 translocation in an insulinindependent manner. Biol. Med. doi: 10.4172/0974-8369.1000s3007 [Epub ahead of print].

Messina, G., Zannella, C., Monda, V., Dato, A., Liccardo, D., De Blasio, S., et al. (2015c). The beneficial effects of coffee in human nutrition. Biol. Med. 7:240.doi: 10.4172/0974-8369.1000240

Mitsuma, T., Hirooka, Y., Mori, Y., Kayama, M., Adachi, K., Rhue, N., et al. (1999). Effects of orexin A on thyrotropin-releasing hormone and thyrotropin secretion in rats. Horm. Metab. Res. 31, 606-609. doi: 10.1055/s-2007-978805

Mochizuki, T., Arrigoni, E., Marcus, J. N., Clark, E. L., Yamamoto, M., Honer, M., et al. (2011). Orexin receptor 2 expression in the posterior hypothalamus rescues sleepiness in narcoleptic mice. Proc. Natl. Acad. Sci. U S A 108, 4471-4476. doi: 10.1073/pnas.1012456108 
Molik, E., Zieba, D. A., Misztal, T., Romanowicz, K., Wszola, M., Wierzchos, E., et al. (2008). The role of orexin A in the control of prolactin and growth hormone secretions in sheep- in vitro study. J. Physiol. Pharmacol. 59, 91-100.

Monda, M., Messina, G., Scognamiglio, I., Lombardi, A., Martin, G. A., Sperlongano, P., et al. (2014). Short-term diet and moderate exercise in young overweight men modulate cardiocyte and hepatocarcinoma survival by oxidative stress. Oxid. Med. Cell. Longev. 2014:131024. doi: 10. $1155 / 2014 / 131024$

Monda, M., Viggiano, A. N., Viggiano, A. L., Fuccio, F., and De Luca, V. (2004). Cortical spreading depression blocks the hyperthermic reaction induced by orexin A. Neuroscience 123, 567-574. doi: 10.1016/j.neuroscience.2003.09.016

Monda, M., Viggiano, A., Viggiano, A., Mondola, R., Viggiano, E., Messina, G., et al. (2008). Olanzapine blocks the sympathetic and hyperthermic reactions due to cerebral injection of orexin A. Peptides 29, 120-126. doi: 10.1016/j. peptides.2007.10.016

Monda, M., Viggiano, A., Viggiano, A., Viggiano, E., Messina, G., Tafuri, D., et al. (2006). Quetiapine lowers sympathetic and hyperthermic reactions due to cerebral injection of orexin A. Neuropeptides 40, 357-363. doi: 10.1016/j.npep. 2006.07.003

Monda, M., Viggiano, A., Viggiano, A., Viggiano, E., Messina, G., Tafuri, D., et al. (2007). Sympathetic and hyperthermic reactions by orexin A: role of cerebral catecholaminergic neurons. Regul. Pept. 139, 39-44. doi: 10.1016/j.regpep.2006. 10.002

Moon, J. H. (2016). Endocrine risk factors for cognitive impairment. Endocrinol. Metab. (Seoul) 31, 185-192. doi: 10.3803/EnM.2016.31.2.185

Moscatelli, F., Messina, G., Valenzano, A., Petito, A., Triggiani, A. I., Ciliberti, M. A. P., et al. (2015). Relationship between RPE and blood lactate after fatiguing handgrip exercise in taekwondo and sedentary subjects. Biol. Med. S3:008. doi: 10.4172/0974-8369.1000s3008

Moura, E. G., and Moura, C. C. (2004). Regulation of thyrotropin synthesis and secretion. Arq. Bras. Endocrinol. Metabol. 48, 40-52.

Nambu, T., Sakurai, T., Mizukami, K., Hosoya, Y., Yanagisawa, M., and Goto, K. (1999). Distribution of orexin neurons in the adult rat brain. Brain Res. 827, 243-260. doi: 10.1016/s0006-8993(99)01336-0

Nishino, S., Arrigoni, J., Shelton, J., Kanbayashi, T., Dement, W. C., and Mignot, E. (1997). Effects of thyrotropin-releasing hormone and its analogs on daytime sleepiness and cataplexy in canine narcolepsy. J. Neurosci. 17, 6401-6408.

Novak, C. M., and Levine, J. A. (2009). Daily intraparaventricular orexin-A treatment induces weight loss in rats. Obesity (Silver Spring) 17, 1493-1498. doi: 10.1038/oby.2009.91

Pasquali, D., Carotenuto, M., Leporati, P., Esposito, M., Antinolfi, L., Esposito, D., et al. (2015). Maternal hypothyroidism and subsequent neuropsychological outcome of the progeny: a family portrait. Endocrine 50, 797-801. doi: 10. 1007/s12020-015-0564-3

Pejovic, S., Vgontzas, A. N., Basta, M., Tsaoussoglou, M., Zoumakis, E., Vgontzas, A., et al. (2010). Leptin and hunger levels in young healthy adults after one night of sleep loss. J. Sleep Res. 19, 552-558. doi: 10.1111/j.1365-2869. 2010.00844.x

Peyron, C., Tighe, D. K., van den Pol, A. N., de Lecea, L., Heller, H. C., Sutcliffe, J. G., et al. (1998). Neurons containing hypocretin (orexin) project to multiple neuronal systems. J. Neurosci. 18, 9996-10015.

Poli, F., Pizza, F., Mignot, E., Ferri, R., Pagotto, U., Taheri, S., et al. (2013). High prevalence of precocious puberty and obesity in childhood narcolepsy with cataplexy. Sleep 36, 175-181. doi: 10.5665/sleep.2366

Pu, S., Jain, M. R., Kalra, P. S., and Kalra, S. P. (1998). Orexins, a novel family of hypothalamic neuropeptides, modulate pituitary luteinizing hormone secretion in an ovarian steroid-dependent manner. Regul. Pept. 78, 133-136.

Riahi, E., Arezoomandan, R., Fatahi, Z., and Haghparast, A. (2015). The electrical activity of hippocampal pyramidal neuron is subjected to descending control by the brain orexin/hypocretin system. Neurobiol. Learn. Mem. 119, 93-101. doi: $10.1016 /$ j.nlm.2015.02.001

Riehl, J., Honda, K., Kwan, M., Hong, J., Mignot, E., and Nishino, S. (2000). Chronic oral administration of CG-3703, a thyrotropin releasing hormone analog, increases wake and decreases cataplexy in canine narcolepsy. Neuropsychopharmacology 23, 34-45. doi: 10.1016/s0893-133x(99)00159-1

Rocca, F. L., Pizza, F., Ricci, E., and Plazzi, G. (2015). Narcolepsy during childhood: an update. Neuropediatrics 46, 181-198. doi: 10.1055/s-0035-1550152

Russell, S. H., Kim, M. S., Small, C. J., Abbott, C. R., Morgan, D. G. A., Taheri, S., et al. (2000). Central administration of orexin A suppresses basal and domperidone stimulated plasma prolactin. J. Neuroendocrinol. 12, 1213-1218. doi: 10.1046/j.1365-2826.2000.00582.x

Russell, S. H., Small, C. J., Sunter, D., Morgan, I., Dakin, C. L., Cohen, M. A., et al. (2002). Chronic intraparaventricular nuclear administration of orexin $\mathrm{A}$ in male rats does not alter thyroid axis or uncoupling protein-1 in brown adipose tissue. Regul. Pept. 104, 61-68. doi: 10.1016/s0167-0115(01)00349-4

Sakurai, T., Amemiya, A., Ishii, M., Matsuzaki, I., Chemelli, R. M., Tanaka, H., et al (1998). Orexins and orexin receptors: a family of hypothalamic neuropeptides and $\mathrm{G}$ protein-coupled receptors that regulate feeding behavior. Cell 92, 573-585. doi: 10.1016/s0092-8674(00)80949-6

Samson, W. K., and Taylor, M. M. (2001). Hypocretin/orexin suppresses corticotroph responsiveness in vitro. Am. J. Physiol. Regul. Integr. Comp. Physiol. 281, R1140-R1145.

Selcher, J. C., Weeber, E. J., Christian, J., Nekrasova, T., Landreth, G. E., Sweatt, J. D., et al. (2003). A role for ERK MAP kinase in physiologic temporal integration in hippocampal area CA1. Learn. Mem. 10, 26-39. doi: 10.1101/lm. 51103

Sellayah, D., and Sikder, D. (2013). Feeding the heat on brown fat. Ann. N Y Acad. Sci. 1302, 11-23. doi: 10.1111/nyas. 12276

Shinno, H., Ishikawa, I., Yamanaka, M., Usui, A., Danjo, S., Inami, Y., et al. (2011). Effect of levothyroxine on prolonged nocturnal sleep time and excessive daytime somnolence in patients with idiopathic hypersomnia. Sleep Med. 12, 578-583. doi: 10.1016/j.sleep.2011.02.004

Silveyra, P., Catalano, P. N., Lux-Lantos, V., and Libertun, C. (2007). Impact of proestrous milieu on expression of orexin receptors and prepro-orexin in rat hypothalamus and hypophysis: actions of Cetrorelix and Nembutal. Am. J. Physiol. Endocrinol. Metab. 292, E820-E828. doi: 10.1152/ajpendo.00467.2006

Sobol, D. L., and Spector, A. R. (2014). Levothyroxine improves subjective sleepiness in a euthyroid patient with narcolepsy without cataplexy. J. Clin. Sleep Med. 10, 1231-1232. doi: 10.5664/jcsm.4210

Suzuki, T., Kohno, H., Sakurada, T., Tadano, T., and Kisara, K. (1982). Intracranial injection of thyrotropin releasing hormone (TRH) suppresses starvationinduced feeding and drinking in rats. Pharmacol. Biochem. Behav. 17, 249-253. doi: 10.1016/0091-3057(82)90078-8

Suzuki, H., Matsumoto, A., and Yamamoto, T. (2009). Orexin-B-like immunoreactivity localized in both luteinizing hormone- and thyroidstimulating hormone-containing cells in the Nile tilapia (Oreochromis niloticus) pituitary. Tissue Cell 41, 75-78. doi: 10.1016/j.tice.2008.06.001

Suzuki, H., Takemoto, Y., and Yamamoto, T. (2007). Differential distribution of orexin-A-like and orexin receptor 1 (OX1R)-like immunoreactivities in the Xenopus pituitary. Tissue Cell 39, 423-430. doi: 10.1016/j.tice.2007.08.001

Szlachcic, A., Majka, J., Strzalka, M., Szmyd, J., Pajdo, R., Ptak-Belowska, A., et al. (2013). Experimental healing of preexisting gastric ulcers induced by hormones controlling food intake ghrelin, orexin-A and nesfatin-1 is impaired under diabetic conditions. A key to understanding the diabetic gastropathy? J. Physiol. Pharmacol. 64, 625-637.

Tamura, T., Irahara, M., Tezuka, M., Kiyokawa, M., and Aono, T. (1999). Orexins, orexigenic hypothalamic neuropeptides, suppress the pulsatile secretion of luteinizing hormone in ovariectomized female rats. Biochem. Biophys. Res. Commun. 264, 759-762. doi: 10.1006/bbrc.1999.1573

Telegdy, G., and Adamik, A. (2002). The action of orexin A on passive avoidance learning. Involvement of transmitters. Regul. Pept. 104, 105-110. doi: 10. 1016/s0167-0115(01)00341-x

Tohma, Y., Akturk, M., Altinova, A., Yassibas, E., Cerit, E. T., Gulbahar, O., et al. (2015). Circulating levels of orexin-A, Nesfatin-1, agouti-related peptide and neuropeptide $\mathrm{Y}$ in patients with hyperthyroidism. Thyroid 25, 776-783. doi: 10. 1089/thy.2014.0515

Tortorella, S., Rodrigo-Angulo, M. L., Núñez, A., and Garzón, M. (2013). Synaptic interactions between perifornical lateral hypothalamic area, locus coeruleus nucleus and the oral pontine reticular nucleus are implicated in the stage succession during sleep-wakefulness cycle. Front. Neurosci. 7:216. doi: 10. 3389/fnins.2013.00216

Triggiani, A. I., Valenzano, A., Ciliberti, M. A. P., Moscatelli, F., Villani, S., Monda, M., et al. (2015). Heart rate variability is reduced in underweight and overweight healthy adult women. Clin. Physiol. Funct. Imaging doi: 10.1111/cpf. 12281 [Epub ahead of print].

Tsujino, N., and Sakurai, T. (2009). Orexin/hypocretin: a neuropeptide at the interface of sleep, energy homeostasis and reward system. Pharmacol. Rev. 61, 162-176. doi: 10.1124/pr.109.001321 
Tsujino, N., and Sakurai, T. (2013). Role of orexin in modulating arousal, feeding and motivation. Front. Behav. Neurosci. 7:28. doi: 10.3389/fnbeh.2013. 00028

Valenzano, A., Moscatelli, F., Triggiani, A. I., Capranica, L., De Ioannon, G., Piacentini, M. F., et al. (2016). Heart-rate changes after an ultraendurance swim from italy to albania: a case report. Int. J. Sports Physiol. Perform. 11, 407-409. doi: 10.1123/ijspp.2015-0035

Vgontzas, A. N., Bixler, E. O., and Chrousos, G. P. (2005). Sleep apnea is a manifestation of the metabolic syndrome. Sleep Med. Rev. 9, 211-224. doi: 10. 1016/j.smrv.2005.01.006

Vgontzas, A. N., Gaines, J., Ryan, S., and McNicholas, W. T. (2016). CrossTalk proposal: metabolic syndrome causes sleep apnoea. J. Physiol. doi: 10. 1113/jp272114 [Epub ahead of print].

Viggiano, A., Chieffi, S., Tafuri, D., Messina, G., Monda, M., and De Luca, B. (2014). Laterality of a second player position affects lateral deviation of basketball shooting. J. Sports Sci. 32, 46-52. doi: 10.1080/02640414.2013.805236

Viggiano, A., Nicodemo, U., Viggiano, E., Messina, G., Viggiano, A., Monda, M., et al. (2010). Mastication overload causes an increase in $\mathrm{O} 2$ - production into the subnucleus oralis of the spinal trigeminal nucleus. Neuroscience 166, 416-421. doi: 10.1016/j.neuroscience.2009.12.071

Viggiano, A., Vicidomini, C., Monda, M., Carleo, D., Carleo, R., Messina, G., et al. (2009). Fast and low-cost analysis of heart rate variability reveals vegetative alterations in noncomplicated diabetic patients. J. Diabetes Complications 23, 119-123. doi: 10.1016/j.jdiacomp.2007.11.009

Winkler, A., Weimar, C., Jöckel, K. H., Erbel, R., Dragano, N., BroeckerPreuss, M., et al. (2015). Thyroid-stimulating hormone and mild cognitive impairment: results of the heinz nixdorf recall study. J. Alzheimers Dis. 49, 797-807. doi: 10.3233/jad-150561
Yang, L., Zou, B., Xiong, X., Pascual, C., Xie, J., Malik, A., et al. (2013). Hypocretin/orexin neurons contribute to hippocampus-dependent social memory and synaptic plasticity in mice. J. Neurosci. 33, 5275-5284. doi: 10. 1523/jneurosci.3200-12.2013

Zhao, X., Zhang, R., Tang, S., Ren, Y., Yang, W., Liu, X., et al. (2014). Orexin-Ainduced ERK1/2 activation reverses impaired spatial learning and memory in

pentylenetetrazol-kindled rats via OX1R-mediated hippocampal neurogenesis. Peptides 54, 140-147. doi: 10.1016/j.peptides.2013.11.019

Zieba, D. A., Kirsz, K., Molik, E., Romanowicz, K., and Wojtowicz, A. K. (2011). Effects of orexigenic peptides and leptin on melatonin secretion during different photoperiods in seasonal breeding ewes: an in vitro study. Domest. Anim. Endocrinol. 40, 139-146. doi: 10.1016/j.domaniend.2010.09.008

Zitnik, G. A. (2016). Control of arousal through neuropeptide afferents of the locus coeruleus. Brain Res. 1641, 338-350. doi: 10.1016/j.brainres.2015.12.010

Conflict of Interest Statement: The authors declare that the research was conducted in the absence of any commercial or financial relationships that could be construed as a potential conflict of interest.

Copyright (C) 2016 Messina, De Fusco, Monda, Esposito, Moscatelli, Valenzano, Carotenuto, Viggiano, Chieffi, De Luca, Cibelli, Monda and Messina. This is an open-access article distributed under the terms of the Creative Commons Attribution License (CC BY). The use, distribution and reproduction in other forums is permitted, provided the original author(s) or licensor are credited and that the original publication in this journal is cited, in accordance with accepted academic practice. No use, distribution or reproduction is permitted which does not comply with these terms. 